\title{
Use of a mucolytic agent (Cytoclair) in the preparation of cell material for the detection of malignant cells in sputum
}

\author{
J. M. GRAINGER AND O. A. N. HUSAIN \\ From the Department of Cytology, Charing Cross Hospital, Fulham Palace Road, London W6 and \\ The Regional Cytology Centre, St Stephen's Hospital, Chelsea, London SWIO 9TH, UK
}

SUMMARY A mucolytic agent, methyl cysteine $\mathrm{HCl}$ (Cytoclair), has been used to obtain a centrifuged cell deposit for the detection of malignant cells in sputum. In 178 sputum samples from 52 patients with primary lung cancer there was a slightly higher rate of detection with the mucolytic method than with the routine method: 54 positives from 27 patients compared with 48 positives from 24 patients. Morphological studies using the mucolytic agent indicated that a millipore filter with fixation of cells in suspension produces a satisfactory cell preparation and is valuable in certain problem cases.

The use of a mucolytic agent in the preparation of cell material from sputum has theoretical advantages. Freed from mucus the cells can be centrifuged and concentrated, and a larger cell sample can be placed on a slide. This can be considered a representative sample. Moreover the use of a mucolytic agent allows preparation of a cell suspension that can be stored for months, from which a slide preparation can be made at any time.

The method of preparation most commonly used in the United Kingdom is that introduced by Papanicolaou (1946), in which parts of a sputum are selected and smeared on a slide, fixed, and later stained.

In order to increase the cell sample, and the diagnostic rate, numerous mucolytic methods have been used, enzymatic, chemical, and mechanical, and trypsin was the first enzyme used as a mucolytic agent (Farber et al., 1953; Takahashi and Urabe, 1963). Enzymatic methods have not had general acceptance. Umiker et al. (1958), using chymotrypsin, concluded that there was no improvement in the percentage of positive smears and that adenocarcinoma and undifferentiated carcinoma were morphologically altered by the digestion. A mechanical method much used in the United States is that described by Saccomanno et al. (1963) and Fern Miller and Woolner (1974), which employs a highspeed blender or homogeniser.

Received for publication 14 November 1977
Recently introduced mucolytic agents that are believed to act by breaking the disulphide bond include acetyl cysteine (Bonime, 1972), methyl cysteine (D. M. D. Evans, personal communication, 1974), and dithiothreitol (Shah and Dye, 1966). A comparison of in vitro sputum-liquefying agents by Hirsch et al. (1969) suggested that methyl cysteine was the most active.

Effective mucolytic agents are now available that are simple to use, and it seemed important to assess the advantages and disadvantages of the method. It appeared to us of particular importance not only to assess the rate of detection of malignant cells, but also to assess the effects of the mucolytic agent on cell morphology. This is the purport of the second part of this paper.

\section{Material and methods}

Methyl cysteine $\mathrm{HCl}$ (Cytoclair) $)^{1}$ was kept at $4^{\circ} \mathrm{C}$ in a closed container and used to prepare a $2 \%$ solution in normal saline. This was also kept at $4^{\circ} \mathrm{C}$, with air excluded, in a $50-\mathrm{ml}$ plastic syringe and used as required. Fresh mucolytic solution was prepared every two to three days. When the sputum arrived in the laboratory two direct smears were made from selected parts and stained by the Papanicolaou method. These two smears are referred to as 'direct'

${ }^{1}$ Methyl cysteine $\mathrm{HCl}$ (Cytoclair) is supplied as a powder by Sinclair Pharmaceuticals Ltd, 8 Oakford Road, Godalming, Surrey, UK. 
smears. The remainder of the specimen was placed in a container, and $5-10 \mathrm{ml}$ of mucolytic solution was added, depending upon the volume of sputum, the aim being to have approximately equal volumes of each. The container was then shaken by hand for about 15 seconds after which it was placed in an incubator at $37^{\circ} \mathrm{C}$ for $1 \frac{1}{2}$ to 3 hours, according to the convenience of the technician. The contents were then centrifuged at $1250 \mathrm{rpm}$ for 5 minutes and the supernatant was discarded; $5 \mathrm{ml}$ of $70 \%$ alcohol was added and the deposit was resuspended. This cell suspension was centrifuged at $1250 \mathrm{rpm}$ for 3 minutes. Most of the supernatant was removed and the deposit was pipetted up and down to make a uniform cell suspension of $0.5-1 \mathrm{ml}$ in $70 \%$ alcohol, the volume depending on the amount of cell deposit. A large drop of this suspension was then placed on gelatin-coated slides (see below), spread evenly, and allowed to dry. Too wet a preparation and too slow drying tend to produce cell clumping.

When dry these slides were stained by the Papanicolaou technique. These were referred to as the 'dried-on' mucolytic slides and were used to compare detection rates for malignant cells.

The alcohol wash and fixation in suspension was found to allow a more even spreading of cells and to eliminate some of the cell debris, thus giving a 'cleaner' smear. Furthermore, the residual suspension could then be stored by simply adding $70 \%$ alcohol to the container.

It was found that smears from cell suspensions fixed in $70 \%$ alcohol remained adherent to the glass while being stained only if an adherent agent, eg, pectin, was used, either by coating the glass slides or mixing with the cell button. We found it most convenient to use gelatin-coated slides, which were made by dipping clean, grease-free slides in $0.5 \%$ gelatin in water ${ }^{1}$ and allowing them to dry. They were stored at $4^{\circ} \mathrm{C}$ in flat trays and used within two weeks.

\section{The trials}

\section{PAR T 1}

The first part of the work carried out was primarily concerned in assessing rates of detection of malignant cells in the direct smears (selective Papanicolaou technique) and the 'dried-on' mucolytic preparations, as described above, from the same specimen.

From the beginning of this trial all the sputa arriving in the two laboratories were considered, unless the specimen was more than $\mathbf{4 8}$ hours old, or there was insufficient specimen, after the direct

${ }^{1}$ The use of $0.5 \%$ gelatin-coated slides was suggested by Mr W. Hamilton, Chief Technician, Histology Department, Hammersmith Hospital, DuCane Road, London UK. smears had been made, to be treated with mucolytic agent, or the specimen was inadvertently 'missed', which rarely happened.

Whether or not the smear was 'satisfactory' was given careful consideration. The commonest cause of an unsatisfactory smear was an insufficient cell sample derived from the bronchial tree. A smear was regarded as an insufficient cell sample when there was, on average, less than one histiocyte of bronchial origin in a microscope field using a $\times 10$ objective and a standard $\times 8$ eyepiece. A smear was also considered technically unsatisfactory for a variety of other reasons, for example, if the cell material had come off the slide during staining or if the centrifuge tube had broken in processing. A smear was not considered unsatisfactory on account of changes in cell morphology because it was considered that, if this was significant, it would be reflected in changes in maligant cell detection rates.

The sputum trial forming the first part of this work was continued for 12 weeks in Charing Cross Hospital and for 30 weeks in St Stephen's Hospital. Experienced technicians, SP, MS, or IZ, screened the direct smears (two slides) and wrote a report and then wrote a separate report later on receipt of the prepared mucolytic 'dried-on' smears (usually one, sometimes two slides). A judgment of suspicious (probably malignant, but requiring further sputa or investigations for confirmation) or malignant was reviewed by one or both of us. Whether the smears were unsatisfactory was decided mainly by one of us (JMG) according to the above criteria. The patients were followed up after a period of six months, mainly by a check on the laboratory files and examination of the patient's notes. In some cases there was a consultation with the general practitioner, radiologist, or clinician.

The patient was regarded as having primary bronchial carcinoma on the evidence of histological section of bronchial biopsy, lymph node, or lung resection material, the evidence of necropsy, or when the subsequent clinical course was strongly indicative. Metastatic carcinoma in the lung was considered only when the extrapulmonary primary was proved and the patient's $x$-ray was suggestive of metastases at the time the sputum was submitted to the laboratory.

PART 2

The second part of this work was carried out after the completion of the first and was designed to compare the cell morphology in various types of mucolytic preparation, both on a slide and on millipore membranes, with the cell morphology in the direct smear. Here the positive sputa from 20 patients with lung cancer (primary and metastatic) were used: 
five patients with epidermoid carcinoma, six with small-cell anaplastic carcinoma, and nine with largecell carcinoma or adenocarcinoma (primary or metastatic).

Two direct smears were prepared, and the remainder of the specimen was treated with Cytoclair solution (as described above). The mucolytic cell suspension was then divided into two. Each portion was centrifuged, and one cell deposit was resuspended in $70 \%$ alcohol, the other in buffered formalin. A portion of each fixed cell suspension was then used to make a 'dried-on' slide preparation and also a millipore filter (Schwinn, 1974) using 1-inch circular filters in a Swinney filter holder. From each of these positive sputa five preparations were compared as follows:

1 Direct smear

2 Millipore preparation \of mucolysed, formalin3 Dried-on preparation $\int$ fixed cells in suspension

4 Millipore preparation \{ of mucolysed, alcohol-

5 Dried-on preparation $\int$ fixed cells in suspension

\section{Results}

\section{PART 1}

Two hundred and forty-four patients had specimens submitted as part of the trial for malignant cells. Of these, 52 were found to have primary lung cancer $(21.3 \%)$ and 13 had pulmonary tuberculosis $(5 \cdot 3 \%)$, which included one patient who had both lung cancer and tuberculosis. Ten patients had extrapulmonary carcinoma, two with radiological evidence of lung metastases, but sputa from these patients were negative for malignant cells.

The 244 patients produced 678 specimens of sputum, but 57 samples could not be used in the trial. This was for a variety of reasons, but most commonly (44 specimens) because there was insufficient sputum, after the direct smears had been made, to allow treatment with the mucolysant.

Thus 621 specimens had both direct and mucolytic preparations and could be used in the trial. The analysis of 'unsatisfactory' slide preparations is shown in Table 1.

Cytological and histological material was available from 44 patients to allow identification of type

Table 1 Number of unsatisfactory sputa based on 621 sputa in trial

\begin{tabular}{lcc}
\hline $\begin{array}{c}\text { Direct smears } \\
\text { unsatisfactory }\end{array}$ & $70(11.3 \%)$ & $\begin{array}{c}51 \text { due to insufficient cell } \\
\text { sample }\end{array}$ \\
$\begin{array}{c}\text { Mucolytic smears } \\
\text { unsatisfactory }\end{array}$ & $71(11.4 \%)$ & $\begin{array}{c}30 \text { technically } \\
\text { unsatisfactory }\end{array}$ \\
$\begin{array}{c}\text { Unsatisfactory by } \\
\text { both methods }\end{array}$ & $41(6.6 \%)$ & $\begin{array}{c}22 \text { had insufficient cell } \\
\text { sample by both methods }\end{array}$ \\
\hline
\end{tabular}

Table 2 Classification of 44 lung tumours from which cytological or histological material was available (according to WHO classification)

Epidermoid carcinoma

Small-cell anaplastic carcinoma

Large-cell carcinoma

Adenocarcinoma

Mixed carcinoid/epidermoid

Adenocarcinoma/epidermoid

according to the WHO method of classification (Kreyberg et al, 1967), and this is given in Table 2.

The 52 patients with primary lung cancer had 178 specimens of sputa in the trial. Table 3 shows the number of positive specimens for each patient related to the cell type. The mucolytic preparation appears to provide a higher detection rate of epidermoid carcinoma while the small-cell anaplastic carcinoma appears to be better detected in the direct smears. There is a small improvement in detection rates if both methods are used.

Table 4 refers to the numbers of patients diagnosed by positive sputa. One patient had a positive direct sputum but the mucolytic preparation was negative, and two patients had positive mucolytic preparations and negative direct smears. Two so-called 'falsepositives' were seen. These two patients had produced abnormal cells in the sputum for more than two years and were under close supervision having submitted many sputa. Review of the cytological material suggested that a broncho-epithelial severe dysplasia or in-situ carcinomatous change was developing. It is our policy to record the finding of cells consistent with a dysplasia or an in-situ neoplastic lesion, and, if all other investigations are negative, the patient should be placed in a close follow-up category. Atypical metaplastic cells were sometimes recorded in a few other cases but there was no evidence that they were seen more often in one type of preparation than in the other.

\section{PART 2}

Compared to fixation in formalin, fixation in suspension in $70 \%$ alcohol gives rise to an increase in orangeophilia of the squames and of the malignant squamous cells but not to any noticeable shrinkage of the cells.

The 'dried-on' mucolytic slide preparations were less clear in cell and nuclear morphology and gave rise to increased density of staining of nuclei and sometimes an apparent fragmentation of the stained nuclear material. Yet whether the fixation was $70 \%$ alcohol or buffered formalin, the morphology of the millipore filter preparation was usually better than that of the direct smears. In 15 out of 30 cases the millipore filter preparations were better than the direct smears, and in only 5 out of 30 were the direct 
Table 3 Detection of malignant cells in specimens of sputa (related to method of preparation and cell type)

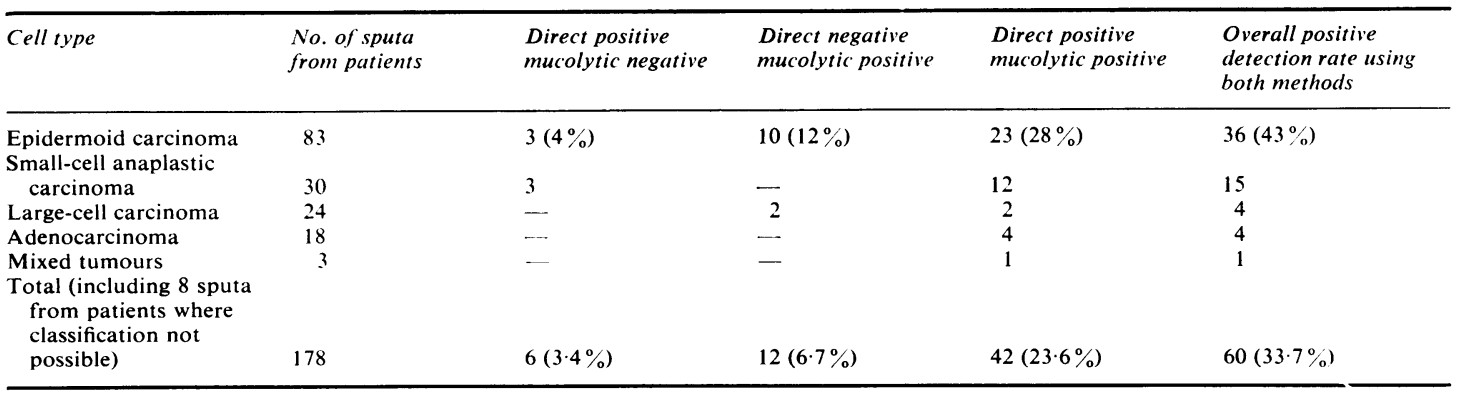

Table 4 Patients diagnosed by sputum cytology (related to method of preparation and cell type)

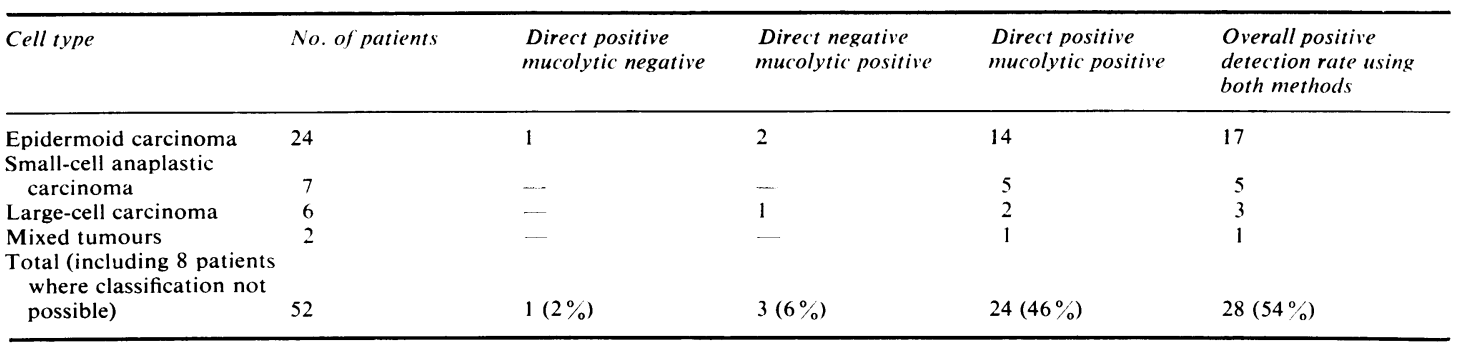

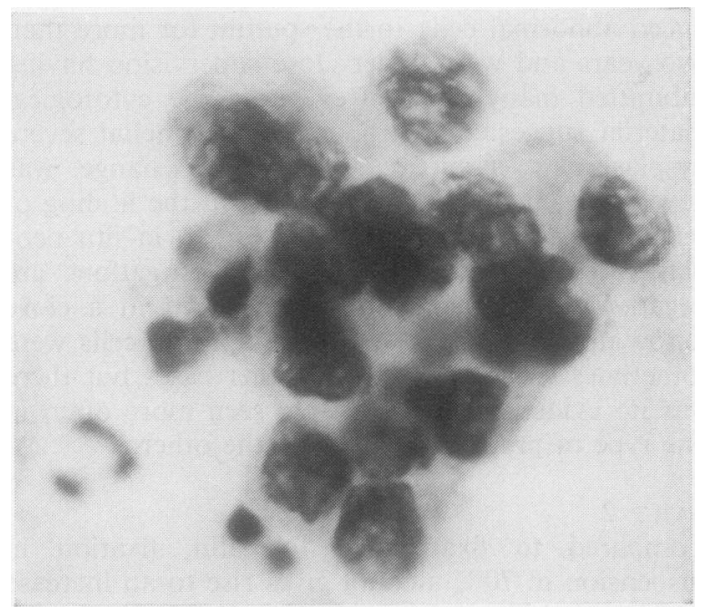

Fig. 1 A malignant cluster in the mucolytic dried-on preparation (negative in the direct smear) from a patient with large-cell carcinoma of lung. Pap stain $\times 880$.

smears morphologically better (Figs 2,3 , and 4).

The millipore filter, as all mucolytic preparations, generally contained more cells and malignant cells, and more and larger cell clusters, and in no way did the mucolysis appear to break up the sheets and clusters of cells. The filter preparations were clearer in that the nuclei were more transparent with more clearly defined nucleoli and nuclear membranes, and free from obscuring mucus. The cytoplasm was clear with more defined cell boundaries. Examination of clusters, especially with the maintained threedimensional effect, often allowed recognition of the characteristic neoplastic glandular formations (adenocarcinoma) (Figs 3 and 4).

Analysis of the first 35 specimens, including five malignant ones, by counting the squames, histiocytes, polymorphs, and malignant cells per average microscopic field showed an increased overall concentration, as reflected by the increased average concentration of polymorphs and histiocytes of 4.6 and $4 \cdot 2$ times respectively. There was, however, a wide variation in degree of concentration, depending on the volume of specimen which could be used for the mucolytic technique. The differential cell counts did not appear to be significantly altered between the two methods. Malignant cell concentration appeared to correlate well with the overall cell concentration and there did not appear to be any loss of malignant cells using the mucolytic process.

\section{Discussion}

Using the criteria given above, 51 out of 621 specimens $(11.3 \%)$ were considered unsatisfactory by the direct method, mainly because of insufficient cell sample (Table 1). Of these 51 specimens classed as insufficient due to lack of cells of bronchial origin in the direct smear, a satisfactory sample was 

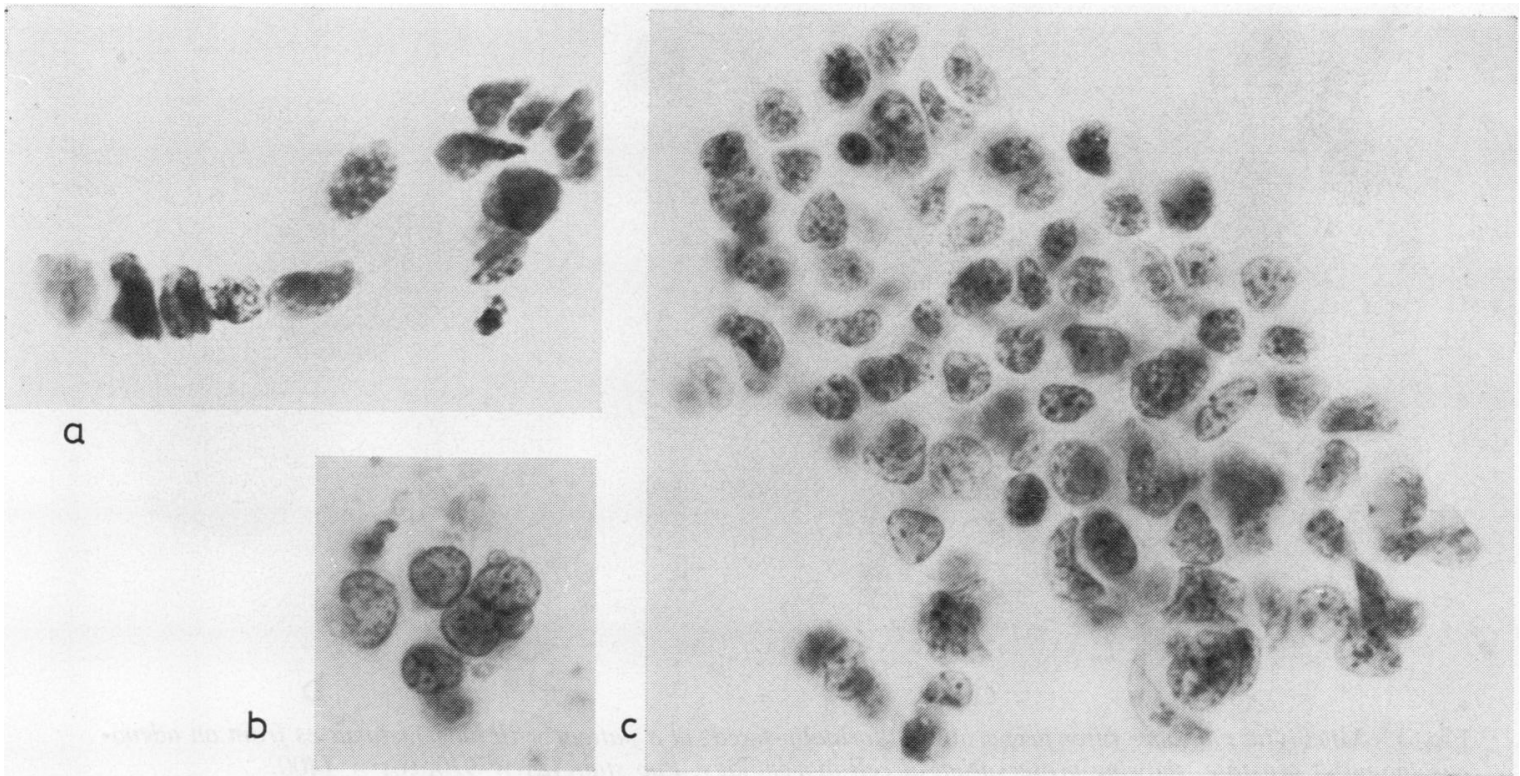

Fig. 2 Malignant cells from small-cell carcinoma of lung:

(a) direct preparation;

(b) formalin-fixed millipore filter preparation; and

(c) formalin-fixed millipore filter preparation. Pap stain $\times 800$.
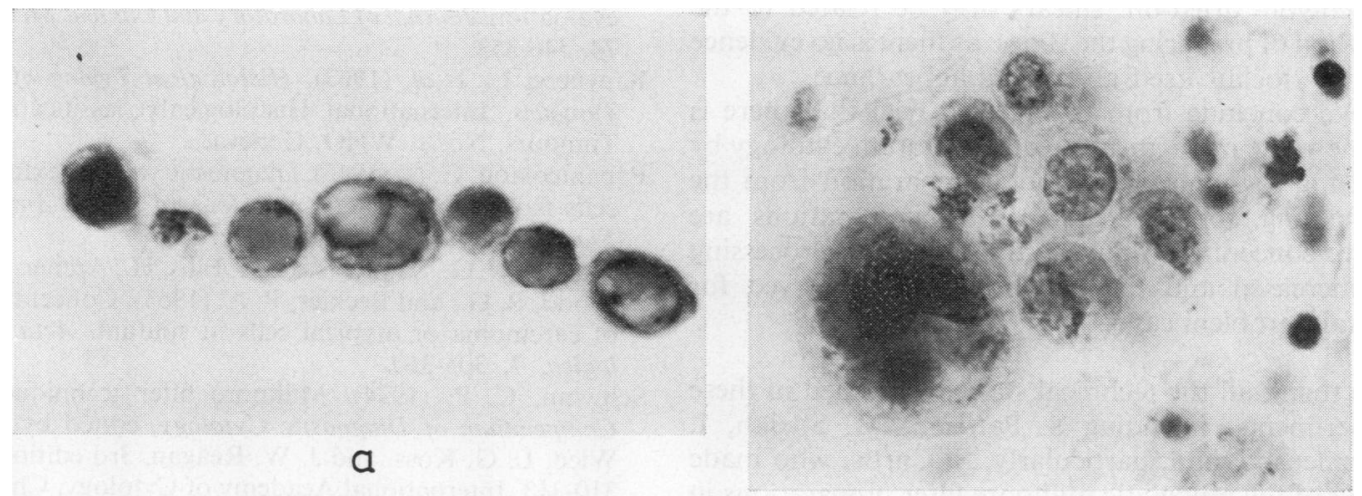

b

Fig. 3 Malignant cells in sputum from a patient with carcinoma of breast metastatic to lung, showing preservation of morphology after mucolysis:

(a) direct preparation; and

(b) mucolytic formalin-fixed millipore filter preparation. Pap stain $\times 840$.

obtained in 31 using the concentration method. However, the mucolytic method is technically more involved and led to a larger number of sputa being regarded as technically unsatisfactory. Tables 3 and
4 show that malignant cells are occasionally identified in the mucolytic but not in the direct specimen (and, less commonly, vice versa). Twelve sputa from three patients were positive in the mucolytic prepara- 


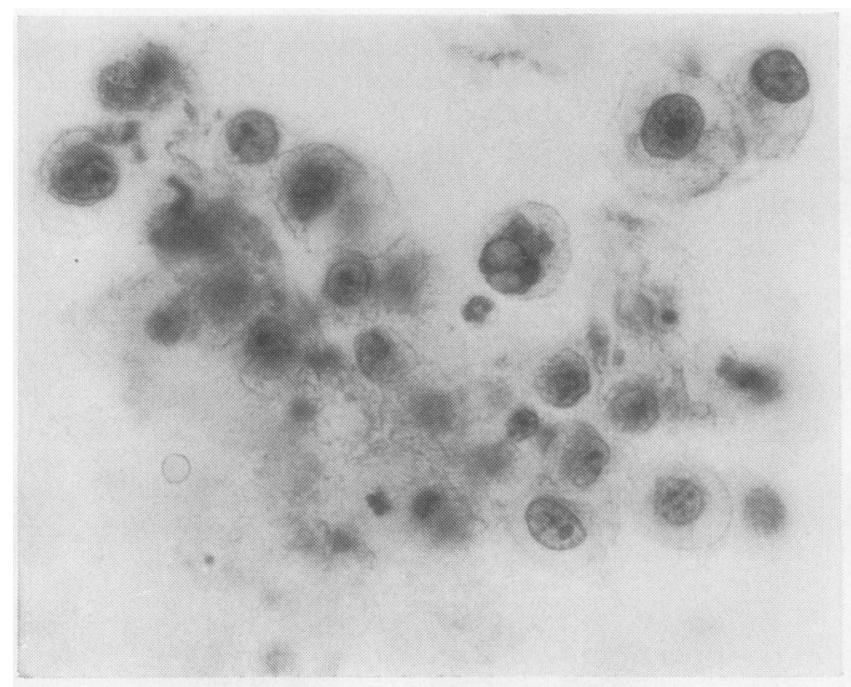

Fig. 4 Mucolytic millipore filter preparations (formalin-fixed) in a patient with lung metastases from an adenocarcinoma of prostate, showing preservation of cell morphology. Pap stain (a) $\times 910,(\mathrm{~b}) \times 1400$.

tion but were negative by the routine method. This increased the patient detection rate from $25 / 52$ $(48 \%)$ to $28 / 52(54 \%)$.

Part 2 of the work suggested that morphology was best when a millipore filter was used, and was not related to the type of fixation. Poor morphology in mucolytic 'dried-on' smears may be related to the method of preparing the slides, as there is no evidence that Cytoclair itself affects cell appearance.

We conclude from this critical trial that there is some value in augmenting direct sputum cytology by making a Cytoclair millipore preparation from the remaining sputum sample; the preparations are more concentrated but the time spent on processing is increased and the method is best reserved for certain problem cases.

We thank all the technical staff who helped in these experiments, including S. Pattison, M. Sheikh, I. Zabnienska, and, particularly, S. Curtis, who made most of the mucolytic millipore filter preparations in Part 2 of the study.

\section{References}

Bonime, R. G. (1972). Improved procedure for the preparation of pulmonary cytology smears. Acta Cytologica, 16, 543-545.

Farber, S. M., Pharr, S. L., Wood, D. A., and Gorman, R. D. (1953). The mucolytic and digestive action of trypsin in the preparation of sputum for cytologic study. Science, 117, 687-690.
Fern Miller, C. T., and Woolner, L. B. (1974). Saccomanno blending technique. In Compendium on Diagnostic Cytology, edited by G. L. Wied, L. G. Koss, and J. W. Reagan, 3rd edition, pp. 256-258. International Academy of Cytology, Chicago.

Hirsch, S. R., Zastrow, H. E., and Kory, R. C. (1969). Sputum liquifying agents: a comparative in vitro evaluation. Journal of Laboratory and Clinical Medicine, 74, 346-353.

Kreyberg, L., et al. (1967). Histological Typing of Lung Tumours. International Histological Classification of Tumours, No. 1. WHO, Geneva.

Papanicolaou, G. N. (1946). Diagnostic value of exfoliated cells from cancerous tissues. Journal of the American Medical Association, 131, 372-378.

Saccomanno, G., Saunders, R. P., Ellis, H., Archer, V. E., Wood, B. G., and Beckler, P. A. (1963). Concentration of carcinoma or atypical cells in sputum. Acta Cytologica, 7, 305-310.

Schwinn, C. P. (1974). Millipore filter techniques. In Compendium of Diagnostic Cytology, edited by G. L. Wied, L. G. Koss, and J. W. Reagan, 3rd edition, pp. 310-313. International Academy of Cytology, Chicago. Shah, R. R., and Dye, W. E. (1966). The use of dithiothreitol to replace $\mathrm{N}$-acetyl-L-cysteine for routine sputum digestion-decontamination for the culture of mycobacteria. American Review of Respiratory Disease, 94, 454.

Takahashi, M., and Urabe, M. (1963). A new cell concentration method for cancer cytology of sputum. Cancer, 16, 199-204.

Umiker, W., Young, L., and Waite, B. (1958). The use of chymotrypsin for the concentration of sputum in the cytologic diagnosis of lung cancer. University of Michigan Medical Bulletin, 24, 265-267. 